\title{
ЯЗЫK03НAHИЕ LINGUISTILS
}

\section{ЧЕРТЫ ПОРТУГАЛЬСКОЙ УСТНОЙ РЕЧИ \\ В ПАМЯТНИКАХ ПИСЬМЕННОЙ РЕЧИ ПОРТУГАЛЬСКОГО ЯЗЫКА ХУІ В. (ПО МАТЕРИАЛАМ ПРОИЗВЕДЕНИЙ Ф. ДЕ ОЛИВЕЙРЫ)}

\author{
FEATURES OF SPOKEN PORTUGUESE LANGUAGE \\ IN MONUMENTS OF WRITTEN LANGUAGE IN PORTUGUESE \\ FROM XVI CENTURY (ON BASE OF WORKS WRITTEN BY F. DE OLIVEIRA)
}

\author{
C.B. Архипов \\ S.V. Arkhipov \\ Московский государственный университет пищевых производств, \\ Россия, 125080, г. Москва, Волоколамское шоссе, д. 11 \\ Moscow State University of Food Production, \\ 11 Volokolamskoye ch. Str., Moscow, 125080, Russia \\ E-mail: lusofon@mail.ru
}

\begin{abstract}
Аннотация
Известно, что в португальском языке письменная и устная формы речи находятся на относительно небольшой дистанции. Письменная форма достаточно хорошо изучена как в синхронии, так и диахронии. Однако степень изученности португальской устной речи значительно меньше. В особенности это касается разговорного языка прошлых веков. Также вне поля зрения исследователей остаётся вопрос о взаимовлиянии обеих форм языка, проникновения черт устной речи в письменный язык. Изучение этих аспектов будет способствовать реконструкции процесса кодификации литературной нормы португальского языка. Автором статьи рассмотрены сочинения португальского автора XVI в. Ф. де Оливейры: доктринальные тексты (грамматика португальского языка, трактаты по военно-морскому делу, кораблестроению) и историческое сочинение (краткое повествовании о кругосветной экспедиции Ф. де Магеллана). Предпринята попытка выявить, классифицировать, объяснить функциональное назначение признаков португальской устной речи XVI в. в произведениях Оливейры. Методом сплошной выборки установлены лексические дублетные формы (слово книжной традиции - слово устной традиции), которые очень характерны и для лексики современного португальского языка. Показана роль диалектизмов в устной речи, в особенности в плане артикуляций звуков. При соотношении способов произношения некоторых слов на основе авторских пояснений были установлены нормативные варианты произношения. Установленные факты проливают свет на процесс становления орфоэпической нормы португальского национального литературного языка.
\end{abstract}

\begin{abstract}
It is known that writing and spoken forms of Portuguese language are not so different. The writing language form was rather studied as in synchrony well as in diachrony. But the spoken language form is not studied in detail. It is relevant particularly to spoken language form from past centuries. The question on mutual influence of both language forms is also not investigated. The infiltration process of colloquial language features into writing language form is of especially interest. The study enables to reconstruct codification process of Portuguese Standard language. The object of this article is to study characteristics
\end{abstract}


of spoken form of Portuguese language in Portuguese-writing texts from $16^{\text {th }}$ century. Sources of this investigation are works written by prominent Portuguese author Fernão de Oliveira: doctrinal texts («Grammar of Portuguese language», treatise on sea war «Sea Warfare», treatise on shipbuilding «Book on Shipbuilding») and brief historical narration about circumnavigation commanded by Fernão de Magalhães «Voyage of Fernão de Magalhães». Author of this article attempts to discover, classify, explain function of Portuguese spoken language features in F. de Oliveira's works. Analysis of old printed and hand-writing texts of Portuguese author enables to receive consequent results. It was discovered lexical doublets forms (word of literary tradition - word of oral tradition) by general selection method. This doublet forms are typical for contemporary Portuguese language vocabulary. It was determinated function of dialecticism in colloquial language, especially in articulation of vowels and consonants. It was established Standard articulation variants of some words on base Oliveira's elucidation and by method of pronunciation mode correlation. Received data enable to elucidate formation process of Portuguese orthoepical standard.

Ключевые слова: Ф. де Оливейра, португальский язык, устная и письменная форма языка. Keywords: F. de Oliveira, Portuguese, spoken and written forms of language.

\section{Введение}

В современной науке о языке большое внимание уделяется устной форме речи. Для её изучения применяются разные методы, например, метод устного опроса (интервьюирования). Широко используются технические средства фиксации и обработки данных разговорной формы языка. Специалист по истории языка лишён таких возможностей. Он имеет в своём распоряжении только печатные или рукописные тексты и методы источниковедческого и лингвистического анализа.

Последнее в полной мере относится и к проблеме изучения черт португальской разговорной речи XVI в., отражённых в сочинениях видного португальского филолога XVI в. Фернана де Оливейры, автора первой грамматики португальского языка и ряда произведений нелингвистического характера. Между тем в его текстах (как печатных, так и рукописных) содержится немало данных о португальской устной речи этого периода, что позволяет представить состояние устной формы португальского языка XVI в. в свете изучения проблемы выработки и становления орфоэпической нормы португальского языка на раннем этапе.

В отечественной и зарубежной португалистике воззрения Ф. де Оливейры на проблемы языка вызывали и вызывают большой интерес у специалистов по лингвистической историографии. Это объясняется особой ролью этого ренессансного филолога в португальской лингвистической традиции. Однако источником этих исследований, как правило, является только один текст Оливейры - «Грамматика португальского языка» (1536). Другие его произведения лингвистами специально не рассматривались. Это связано с тем, что они посвящены проблемам не лингвистики, а вопросам военно-морского дела, кораблестроения, истории кругосветных путешествий. Между тем в этих текстах имеется большой языковой материал, представляющий значительный научный интерес для истории португальского языка в разных аспектах (фонетика, фонология, графика, слогоделение, акцентология, лексикология). Особо значимыми являются замечания португальского автора, окказионально вставленные в тексты по маринистике. Они представляют собой размышления Оливейры лингвистического характера (проблемы номинации и терминообразования), объяснения этимологии, семантики, произношения ряда слов.

Целью данного исследования является изучение инфильтрации черт устной речи в памятники письменной речи, в особенности тексты доктринального характера, каковыми являются сама грамматика, а также трактаты по военно-морскому делу и кораблестроению. Для достижения поставленной цели автор ставит перед собой ряд задач: 1) проанализировать замечания грамматиста по поводу произношения ряда слов с целью выявле- 
ния нормативного произносительного стандарта; 2) методом сплошной выборки выявить варианты одних и тех же слов; 3) сопоставить эти варианты с данными португальской диалектологии; 4) определить какой вариант относится к книжной традиции, а какой используется в устной речи; 5) показать роль лексических заимствований на португальское произношение.

\section{Основная часть}

\section{Интра- и экстралингвистические факторы устной речи}

Изучение признаков португальской устной речи в указанный период представляет особую научную ценность в свете исследования проблемы кодификации литературной нормы португальского национального языка. Именно в XVI в., когда жил и творил Ф. де Оливейра, этот процесс находился на ранней стадии. Оливейре, как первому португальскому грамматисту, в данном кодификационном процессе принадлежит особая роль. Видный специалист по португальской лингвистической историографии М.А. Косарик объясняет это тем, что «устная речь выступает в его (Оливейры - C.A.) грамматике и как основа фиксируемой нормы, и как объект кодификации, причём приоритет остаётся именно за устной, звучащей речью. Это проявилось в преимущественном внимании к фонетике, в призывах "зафиксировать речь наших людей и отсюда вывести правила". Показательны ссылки Оливейры на слышимые им формы (XXIV, XIV)» [Косарик 1991, с. 76].

К этим данным относятся указания португальского автора на способы артикуляций звуков, рассмотрение слога как отдельного уровня языковой системы и тесно связанной с этим аспектом проблемы ударения, объяснения произношения тех или иных слов, слияние слов в речевом потоке (явления фоносинтаксиса). Примечательно, что эти данные, хотя и неравномерно, содержатся не только в грамматике, но и в трактатах по военно-морскому делу и кораблестроению.

В начале грамматики Оливейра говорит о факторах, влияющих на речь человека. В частности, это особенности функционирования речевого аппарата: «Mas fegundo a difpofição da lingua corporal afli vemos formar diuerfas as vozes hũas çeçiofas/outras tartaras: e muitas cõ muitos defeitos e tãbẽ cõ fuas perfeições» - «но в зависимости от положения языка мы образуем разные звуки, одни шепелявые, другие гортанные, и многие со многими недостатками и также со своими достоинствами» ${ }^{1}$; - «Porq̃ como efte orgão da lingua e boca he mais milhor difpofto afli cumpre milhor feu ofiçio: bẽ ou mal difpofto (efte orgão da lingua e boca - C.A.) pode fer em calidades e feição:calidades como feco ou humedo:feição como dẽtes grãdes ou defuiados» - «Ибо язык и рот устроены наиболее лучшим образом так, чтобы лучше выполнять своё предназначение; хорошо или плохо подготовленный к речи (язык и рот - C.A.) может влиять на качества звуков: на качество звука влияют сухость или влажность, особенность звучания зависит от больших или кривых зубов» [Oliueyra 1536, A iij v.].

Грамматист также называет другой фактор, который влияет на речь, - это обычай, которому следуют люди. Как явствует из текста этого лингвистического трактата, многие люди (очевидно, португальцы) плохо говорят из-за того, что опираются в своей речи на плохой обычай: «e tambem muitos falão muito mal: fo com mao coltume não mais» - «и также многие плохо говорят из-за плохого обычая, не более того». Однако Оливейра объясняет этот недостаток природными и географическими условиями: «Е e muito de culpar efte defeyto das calidades ferem diuerfas: nas quaes tem dominio as condições do çeo e terra em que viuem os homẽs» [Oliueyra 1536, A iij v.] - «Причиной этого недостатка являются разные условия, в которых живут люди, и на которые влияют солнце и земля».

Также португальский лингвист XVI в. выделяет этнический фактор. По его словам, разные народы по-разному произносят звуки и слова: «vem que hũas gentes formão fuas vozes mays no papo como caldeus|e arabigos/e outras nações cortão vozes a p̃ fandolle mays em feu falar» - «очевидно, что одни народы образуют свои звуки больше в горле, как халдеи и

\footnotetext{
1 Здесь и далее перевод цитат из текстов Ф. де Оливейры автора $-C . A$.
} 
арабы, а другие народы сокращают слова, ускоряясь в своей речи». Речь португальцев грамматист характеризует как неторопливую и хорошо артикулируемую: «mas nos falamos com grande r $^{0}$ poufo como homẽs affentados: e não fomente em cada vo3 per fy mas tambem no ajuntamento» [Oliueyra 1536, A iij r.] - «но мы говорим очень спокойно как степенные люди, и не только в каждом отдельном звуке, но также и в соединении слов».

Значительную часть грамматики (12 глав из 50, с VIII по XVIII главу включительно) Оливейра посвящает подробной характеристике звуков португальской речи, способов их произношения. Сопоставление португальского фонетического строя, детально рассмотренного ренессансным лингвистом, с современным состоянием позволяет увидеть, что португальская фонетика XVI в. и фонетика современного португальского языка в его пиренейском варианте достаточно схожи [Голубева 1981].

Португальский автор не только говорит о звуках и их правильной артикуляции, но и иногда объясняет, как следует произносить те или иные слова. Примечательно, что эти указания мы находим в трактатах по морскому делу. Так, в «Arte da guerra do mar» (1555) («Искусство войны на море») есть замечание о том, что португальцы приспосабливают к своему произношению заимствованные из других языков слова: «Muytos uocabulos tomão os noflos homẽs doutras nações, que o pouo por não faber feu nacimento corrompe tirando ou pondo ou mudãdo letras» [Oliueyra 1555 a, f. xliiij] - «наши люди берут у других народов много слов, и народ, не зная их происхождение, портит их, вставляя или меняя звуки».

В этой связи интересно толкование португальским автором произношения слова «проход» в его разных вариантах - cossia / coxia: «A que eu chamo coffia lhe chamam coxia mas nem elles nem eu acertamos, porque ella fe deue chamar corfia de curfar qua per ella curfam e andam os homẽs na golle porem coxia he pronunciaçam fea e mourifca» [Oliueyra $1555 \mathrm{a}, \mathrm{f}$. xliiij] - «То, что я называю collia, они называют сохіа, но ни они, ни я не произносим правильно, поскольку это слово следует называть corfia от слова curfar, поскольку по нему (проходу - C.A.) проходят и ходят люди в потоке, однако сохіа - это плохое и маврское произношение». Таким образом, вариант этого слова с регрессивной ассимиляцией (cossia) и вариант с палатальным [š] (сохіа), согласно Оливейре, не соответствуют португальской произносительной норме. Образцом, с точки зрения автора, является вариант corsia, который наиболее близок к латинскому этимону cursare (непрерывно бегать, бежать без остановки).

В том же трактате португальский автор довольное подробно объясняет произношение слова comitre (помощник капитана). В этом толковании он подчёркивает роль двойного иноязычного влияния на португальское произношение: «Comitre he pronunciaçam francefa, a qual os noflos tomarão de França com outras muytas, e quer dizer companheyro do meftre» [Oliueyra 1555 a, f. xliiij] - «Comitre - это французское произношение, которое наши заимствовали из Франции со многими другими словами, и это слово означает помощник капитана».

Далее он говорит о том, что слово comitre забыто, поскольку португальцы уже не используют галеи (военные корабли). В дальнейшем это слово было заимствовано генуэзцами в виде comito. И здесь возникает интересная в лингвистическом плане деталь: Оливейра критикует вариант генуэзцев. Он считает, что их язык худший среди итальянцев, но, тем не менее, португальцы заимствуют у генуэзцев это и другие слова в плохом произношении: «porem nos pollo muyto tempo que ha que deyxamos o vfo das galees efquecenos jaa efte e outros vocabulos dellas, e porque agora ouuimos algũs genouefes que por defaftre aqui vieram ter nam dos mays primos, como quer que a fua lingoa feja a pior da Jtalia tomamos delles affy nefte nome como em outros rũys pronunciações e imperfeytas como elles acoftumam» [Oliueyra 1555 a, f. xliij].

В качестве другого примера дурного генуэзского влияния Оливейра приводит слово chufma (корабельная команда). И подобно примеру со словом corsia, грамматист полагает, что вариант churma правильнее, так как он ближе к латинскому этимону turba (толпа, 
масса, куча): «Efte tem cuydado da churma, que tambem os genouefes conforme a feu m ro pronũciar dizem chufma cõ efte letra.s.em lugar de.r. porẽ churma com.r.fe deue pronunciar quafi turbo, porque finifica a cõpanhia vulgar e mays comũ da galee, $\tilde{q}$ em latim fe pronũcia turba» [Oliueyra 1555 a, f. xliiij].

Однако в данном случае Оливейра не точно определяет этимологию слова churma. Слово turba в латинском языке означает «толпа, масса, куча» как в отношении людей и животных, так и в отношении неодушевлённых предметов. Слово turma означает конный отряд, состоящий из 30-32 человек. Кроме этого, turma фонетически ближе к churma, чем turba.

Далее португальский филолог даёт рекомендацию по произношению формы множественного числа слова ministrel (средневековый поэт и музыкант). Так, он не советует использовать форму miniftreys, так как она похожа на слово caniftreys. Вариант miniftris кажется Оливейре лучшим, чем miniftreys: «E não diga ninguẽ miniftreys porque fe parece muyto cõ caniftreys, miniftris he milhor pronunciação, e mays acoftumada, ainda que feja hũ pouco delgada» [Oliueyra 1555 a, f. xlvl]. Сам же автор использует в трактате форму miniftrijs.

Такого же рода рекомендацию мы находим относительно слова тос̧а̃o (движение). Оливейра возражает против формы mouções, поскольку оно схоже со словом mouço de galinha (зоб у курицы): «E nam lhe chame ninguem mouções q̃ parece mouço de galinha. Moçam q̃r dizer mouimento/e he palaura latina que os latinos pronunciam motio, e nos a deuemos pronunciar moçam» [Oliueyra $1555 \mathrm{a}, \mathrm{f} . \mathrm{lj}$ ].

\section{Роль диалектизмов в устной речи}

Как известно, признаком устной речи могут быть и диалектизмы. В ходе анализа произведений Ф. де Оливейры и на основе данных португальской диалектологии были выявлены слова из разных диалектных зон Португалии. Так, диалектная форма слова formoso - fermoso (красивый), распространена в Траз-уж-Монтуш (исторический регион на северо-востоке Португалии). Эта форма встречается почти во всех изучаемых текстах Оливейры: fermofo / fermofos / ferm $\omega$ fos, fremo $\int$, fermo $\int$ os. Но в данном случае следует заметить, что наряду с этой диалектной формой грамматист использует и форму formofo / form $\omega$ fos которая и стала впоследствии нормативной. Указанием на диалектную принадлежность может служить чередование дифтонгов ou / oi, которое мы также находим у Оливейры. И действительно, исследования в области современной португальской диалектологии подтверждают этот факт [Veloso Pratas Dias 2014].

Слова alifantes (слоны), chauelhas (деревянные гвозди), empecilhos (преграды) встречаются в местности Баррозан, находящейся в субрегионе Алту-Траз-уж-Монтеш. Также к северной диалектной зоне относится слово саybros (перекладины, балки). Оно зарегистрировано в исторической провинции Минью (северо-запад Португалии) [de Pratt 1911, 150], [Braga Barreiros 1937, 140, 152, 158], [Oliueyra 1555 a, f. 252 r.], [Oliueyra 1580, $130,138]$.

Центрально-южная диалектная зона (Эстремадура) представлена словом boticairo лавочник, аптекарь. Признаком южных диалектов является стяжение дифтонга [о ${ }^{u}$ в закрытый монофтонг [о]. Этот процесс наблюдался уже в XVI в., когда жил Ф. де Оливейра. Об этом свидетельствуют слова оriueз (ювелир), oriuezaria (ювелирная мастерская) [Oliueyra 1536, D vij v.], [Leite de Vasconcellos, 1890-1892. 19; 1897-1899, 146].

Приведённые примеры диалектизмов показывают, что в языковой практике португальского лингвиста отражены диалектные особенности разных частей Португалии. Это объясняется тем, что Оливейра, будучи уроженцем Севера страны, много путешествовал по Португалии и подолгу жил в разных её регионах.

\section{Устная речь на уровне фоносинтаксиса}

Выше были процитированы слова Оливейры о том, что португальцы говорят неторопливо. Однако это не означает, что португальская устная речь того времени была лишена некоторой динамичности. Сам автор свидетельствует, что португальцы любят сокра- 
щать слова: «Tambem fomos amigos de cortar as vozes». Также автор пишет, что когда одно слово оканчивается на гласный звук, а другое слово начинается также на гласный, то эти гласные сливаются в один звук: «Quando hũa dição acaba em vogal e outra dição logo começa tambẽ em vogal fe fão ambas dhũ mefmo genero mefturanfe ambas e fazẽ hũa vogal» [Oliueyra 1536 , B viij v.].

Как в печатных, так и рукописных текстах Оливейры содержится достаточно много примеров этого явления. Например, словосочетание até agora (до сих пор) в кразисе имеет вид ategora, ategora, ateegora. По такой же модели образованы eftoutro, eftoutro, eftoutras, где este (этот) + outro (другой). Есть примеры таких комплексов, состоящих из трёх слов: comeeffoutros - como esses outros (как эти другие); paras armas - para as armas (для вооружений) [Olieura 1536, В iiij v.], [Oliueyra 1555 a, f. xxxj, xxxij, xxxiij], [Oliueyra 1580, p. 3, $49,84,132]$. Современные исследования также подтверждают, что существует различие между слоговой структурой письменной и устной речи [Meireles 2018].

\section{Слова книжной и устной традиции}

Следы устной речи можно увидеть на примере этимологических дублетов. Благодаря наплыву латинизмов в португальский язык, как и в другие романские языки, образовались лексические пары, где один элемент - это латинизм, другой - португализм. Данная дихотомия имеет сопутствующий признак: книжная форма (латинизм) - устная форма (португализм).

Приведём ряд примеров таких лексических пар.

Книжная форма (латинизм)

atribuido - присвоенный

delicada - нежная, тонкая

elemento - составная часть, стихия

materia - вещество, материя

providencia - предосторожность
Устная форма (португализм)

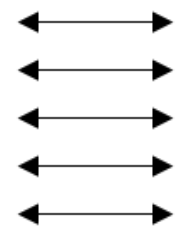
atrevido - смелый, дерзкий delgada - тонкая, худая alimento - пища, питание madeira - дерево, древесина prudencia - благоразумие

\section{Народный фольклор как проявление устной речи}

К чертам устной речи в текстах Оливейры можно отнести употребление пословиц. Пословицы, как известно, являются достоянием устного народного творчества. Оливейра опирается в своих сочинениях (в основном доктринальных текстах) на этот пласт в дидактических целях, для подкрепления своей аргументации. О том, что изречения с поучающим смыслом представляют собой пословицы, свидетельствуют авторские пояснения, такие как conforme ao proverbio (в соответствии с пословицей), fegũdo o prouerbio q̃ di3 (согласно пословице, которая гласит), diz о prouerbio vulgar (народная пословица гласит).

Например, в «Arte da guerra do mar» («Искусство войны на море») употребляется пословица, связанная с войной: «А boa guerra faз a boa paз» [Oliueyra 1555 a, f. x] - «Хoрошая война делает хороший мир». В этом же военно-морском трактате встречаются пословица, дающая совет как стать искусным в морском деле: «vfa e feraas meftre» - «Применяй на практике и станешь мастером». Другой пословицей Оливейра призывает не быть невеждой: «Mal julga o cego acerca das cores» - «Слепой не разбирается в цветах, красках». Кроме того, автор посредством пословицы критикует трусость: «Achaques aa corefma por nam gejũar» [Oliueyra 1555 a, f. lxvij] - «Быть больным в Великий пост, чтобы не поститься», «Achaq̃s al uiernes por no aiunar le» [Oliueyra 1555 b, f. 251 v.] - «быть больным в пятницу, чтобы не поститься». В трактате «Liuro da fabrica das naos» («Книга о строительстве кораблей») мы находим пословицу, с помощью которой Оливейра допускает разные способы, применяемые в кораблестроении: «quantas fão as cabeças tantos fão os Sentidos» - «сколько голов, столько и умов». Пословица «О auarento por hum pão perde cento» [Oliueyra 1580, pp. 49, 66] соответствует русской пословице «скупой платит 
дважды». При помощи этой пословицы Оливейра порицает мастеров-корабелов, которые экономят на материалах.

\section{Заключение}

В данной статье мы предприняли попытку исследовать признаки португальской устной речи XVI в. Источниками исследования послужили печатные и рукописные тексты португальского автора XVI в. Фернана де Оливейры. В начале исследования были рассмотрены факторы, влияющие на речь человека. Условно их можно обозначить как анатомический, физико-географический, этнический факторы, фактор хорошего или плохого обычая. Отдельно автор говорит об иноязычном влиянии. Однако это замечание касается заимствований. Следы устной речи были выявлены на примере фонетических и лексических диалектизмов. Также наличие признаков устной речи показано на уровне фоносинтаксиса (слияние двух-трёх слов в одно). Уровень предложения, высказывания был продемонстрирован с помощью пословиц.

Проделанный анализ позволяет сделать следующий вывод: письменные памятники португальского языка XVI века в печатной и рукописной формах репрезентативно отражают черты португальской устной речи в указанный период. Кроме того, складывающая литературная норма португальского языка содержит много элементов разговорного языка. Сделанные автором выводы вносят в вклад в изучение проблемы выработки и становления орфоэпической нормы португальского национального литературного языка на раннем этапе (XVI в.).

\section{Список использованных источников}

1. Oliueyra F. de. 1536. Grammatica da lingoagem portuguefa / [Fernão Doliveira]. 1536. - Em Lixboa : e[m] cafa d'Germão Galharde, 27 Ianeyro 1536. - [38] f.

2. Oliueyra F. de. 1555. Arte da Guerra do mar / nouamente efcrita per Fernando Oliueyra ... Em Coimbra : Iohão Aluerez [sic] 4 Iulho 1555. - [4], 9-80 f. ; $4^{\circ}$ [21].

3. Oliueyra F. de. 1555 b. Ferdinandi Oliveri de Sancta Columba [1507-85] opera duo: 1555. Ars nautica, autographa. - Viagem de Fernão de Magalhães, Jecundum narrationem cuiufdam focii et Juppletus ex aliis fontibus, lufitanice. XVI [1555]. 1 deel, geschreven op papier, 255 fol ; ca. 310x215, ca. 298x190/195, ca. 305-205 mm. 255 f.

4. Oliueyra F. de. 1580. Liuro da fabrica das naos / [...] compofto de nouo $\mathrm{p}[\mathrm{e}]$ llo licenciado Fernando Oliueyra [Ca. 1580]. - [3] f., [164] p., enc. : papel, il. ; $31 \mathrm{~cm}, 164$ p.

5. Leite de Vasconcellos J. 1897-1899. Dialectos extremenhos. Revista Lusitana. Vol. V. Lisboa: $137-147$.

\section{Список литературы}

1. Голубева Е.Г. 1981. Фонетика португальского языка. М., Высшая школа, 119 с.

2. Косарик М. А. 1991. Ранние португальские грамматики и трактаты о языке (к историилингвистических учений). Дисс. ... канд. филол. наук. Москва, 257 с.

3. Bechara E. 2010. Estudo da Língua Portuguesa: textos de apoio. Brasília, FUNAG, 420 p. $239-303$.

4. Braga Barreiros F. 1937. Vocabulário barrosão. Revista Lusitana. Vol. XXXV. Lis boa:

5. de Pratt O. 1911. Linguagem minhota. Revista Lusitana. Vol. XIV. Lisboa: 145-168.

6. Fonte J. Simões. 2014. As Vogais na Diacronia do Português: uma interpretação fonológica de três momentos da história da língua. Tese (Doutorado). São Paulo, UNESP, Araquara, 351 p.

7. Gomes Pereira A. 1911. Costumes e linguagem popular de Murça. Revista Lusitana. Vol. XIV. Lisboa: 82-87.

8. Meireles, V. 2018. Sequências vocálicas e o acento de palavra do Português. In: Uma História de Investigações sobre a Língua Portuguesa: Homenagem a Silvia Brandão. São Paulo: Blucher: 183-192.

9. Queriquelli L.-M. 2016. Filología portuguesa: Florianópolis, UNIASSELVI, 176 p. 
10. Veloso Pratas Dias A.-P. 2014. A variação ou - oi em Portugal Continental: Delimitação das áreas geográficas com maior incidência do ditongo oi. Diacrítica. № 28/1. Série Ciências da Linguagem: 51-72.

\section{References}

1. Golubeva E.G. 1981. Fonetika portugal'skogo yazyka [Portuguese Phonetics]. M., Vysshaya shkola, $119 \mathrm{p}$.

2. Kossarik M. A. 1991. Ranniye portugal'skiye grammatiki i traktaty o yazyke (k istorii lingvistichestikh ucheniy) [Early Portuguese grammars and treatises on language (on the history of linguistic teachings)]. Diss. ... cand. filol. sciences. Moscow, $257 \mathrm{p}$.

3. Bechara E. 2010. Estudo da Língua Portuguesa: textos de apoio. Brasília, FUNAG, 420 p. 239-303.

4. Braga Barreiros F. 1937. Vocabulário barrosão. Revista Lusitana. Vol. XXXV. Lisboa:

5. de Pratt O. 1911. Linguagem minhota. Revista Lusitana. Vol. XIV. Lisboa: 145-168.

6. Fonte J. Simões. 2014. As Vogais na Diacronia do Português: uma interpretação fonológica de três momentos da história da língua. Tese (Doutorado). São Paulo, UNESP, Araquara, 351 p.

7. Gomes Pereira A. 1911. Costumes e linguagem popular de Murça. Revista Lusitana. Vol. XIV. Lisboa: 82-87.

8. Meireles, V. 2018. Sequências vocálicas e o acento de palavra do Português. In: Uma História de Investigações sobre a Língua Portuguesa: Homenagem a Silvia Brandão. São Paulo: Blucher: 183-192.

9. Queriquelli L.-M. 2016. Filología portuguesa: Florianópolis, UNIASSELVI, 176 p.

10. Veloso Pratas Dias A.-P. 2014. A variação ou - oi em Portugal Continental: Delimitação das áreas geográficas com maior incidência do ditongo oi. Diacrítica. № 28/1. Série Ciências da Linguagem: $51-72$.

\section{Ссылка для цитирования статьи For citation}

Архипов С.В. 2020. Черты португальской устной речи в памятниках письменной речи португальского языка XVI в. (по материалам произведений Ф. де Оливейры). Вопросы журналистики, педагогики, языкознания, 39 (1): 75-82. DOI 10.18413/2712-7451-2020-39-1-75-82

Arkhipov S.V. 2020. Features of spoken portuguese language in monuments of written language in portuguese from XVI century (on base of works written by F. de Oliveira). Issues in Journalism, Education, Linguistics, 39 (1): 75-82. (in Russian). DOI 10.18413/2712-7451-2020-39-1-75-82 